\title{
Cultural Values Regarding ChILdREn AND FAMILY: THE CULTURAL MEANING OF PARENT-CHILD RELATIONSHIPS
}

\author{
GISELA TROMMSDORFF
}

\section{Introduction}

Culture is conceived here as a complex meaning system interrelated with ecological and socioeconomic conditions and individual development. Thus, culture is seen as constituting the relevant conditions for development by penetrating all spheres of economic, social, and individual processes, and at the same time being influenced by these processes. Culture provides constraints and resources that are part of individual development. Human development can therefore be seen as a product of culture, as affecting culture, and as being part of a cultural niche, thus fostering interrelations between culture and individual behaviour.

This view is influenced by theoretical assumptions of the influential Six Cultures Study by Whiting and Whiting (1975), the multilevel ecological approach by Bronfenbrenner (1977), the culture-ecological approach by Berry, Poortinga, Segall and Dasen (1992, 2002; Trommsdorff and Dasen 2001), the value approach (e.g., Hofstede 1980; in press), the developmental niche hypothesis (Super and Harkness 1997), and the developmental paths approach (Greenfield, Keller, Fuligni, and Maynard 2003; Rothbaum, Pott, Azuma, Miyake, and Weisz 2000) (for an overview see Trommsdorff, in press $\mathrm{a}, \mathrm{c}$ ).

These approaches have in common that it is necessary to 'peel the onion' of culture, and to take the complex characteristics of culture seriously when explaining individual development. One (and maybe the most difficult) problem lies in the task of theoretically bridging the context and the person. One promising step in this direction is the attempt to study the cultural meaning and its effect on individual behavior (Boesch 1991; Bruner 1990, 1996). Thereby, the cultural context and its psychological meaning are analysed with respect to their functions inside and 
outside the psychological system of the individuals. The focus of this approach is on how culture and psyche 'make each other up'.

In the first section of this chapter, the theoretical framework is introduced. This is followed by a brief description of a complex sociodemographic problem, the description of an ongoing cross-cultural study, and some recent empirical results. In the concluding part, an outline for future research on the transmission of cultural meaning is presented.

\section{Cultural and Individual Values as Different Levels of Analyses}

There are many difficulties to be solved when studying the cultural meaning system empirically. The value theories are well known for their attempt to bridge the context and the person by introducing the concept of value orientations. The influential value theory by Hofstede (1980; 2001 ; in press) identifies global aspects of culture on the basis of general (and national) cultural values such as individualism and collectivism, power distance, uncertainty avoidance, masculinity/femininity, and time perspective (Hofstede 1980, 2001, in press). Hofstede's approach has created several misunderstandings and led to wrong conclusions, including the wrong assumption that individualism/collectivism represents the most important dimension and the other dimensions could be neglected, the assumption that these values constitute two opposite poles of one dimension, and the assumption that cultural and individual values overlap. The first assumption has been refuted by other approaches, such as the universalistic value theory by Shalom Schwartz (Schwartz 1992, 2004; Schwartz and Bilsky 1990) who demonstrated a multidimensional structure of a universal value system consisting of seven dimensions. Schwartz showed that cultures can be described by other than Hofstede's value dimensions. Also the assumption of a one-dimensionality of individualism/collectivism cannot be empirically validated and has been frequently criticized (e.g., Kagitcibasi 1996; Oyserman, Coon, and Kemmelmeier 2002). Furthermore, the assumption of an overlap between cultural and individual values cannot be accepted since cultural and individual values are related to different concepts and to different methodological approaches. Triandis (1995) has therefore differentiated between the cultural value of individualism and the individual value of ideocentrism on the one hand and cultural value of collectivism and the individual value of allocentrism on the other hand in order to specify the cultural and the individual level. This necessary differentiation precedes the em- 
pirical testing of the relations between the cultural context and the individual behavior.

Cultural values function on a different level than individual value orientations. A focus on whole cultural entities takes into account political institutions, religious orientations, socioeconomic, and sociodemographic conditions. A focus on the person takes into account the individual goals, beliefs, and behaviour. Accordingly, cultural values are part of a complex system of ecological, socio-economic, and demographic conditions. They may overlap with individual value orientations of certain populations from the same or even from other cultures; the degree of overlap may be an indicator for cultural heterogeneity and socio-cultural change.

The relation between cultural and individual values is of special interest in culture-psychological research. The interesting question is whether cultural values can be transformed into individual values, and how this process can be described. From a developmental psychological perspective, this question is dealt with by socialization theories (Grusec and Hastings, in press). One aspect of socialization is to prepare children to adopt cultural values and internalize them such that they can achieve optimal development in their specific cultural context. Such socialization is effective via several interconnected levels of transmission: the macro, the meso-, and the micro-levels (Bronfenbrenner 1977). The transmission of values through parent-child interactions is only one specific process. In developmental psychology, the impact of parental discipline as part of the transmission belt has been of significant interest in various studies (Grusec and Goodnow 1994). However, most of these studies were carried out in Western countries. They have neglected the cultural context and the respective cultural values and related meaning system, thus ignoring that a specific parenting style can have very different effects on child development (Chao and Tseng 2002; Rothbaum and Trommsdorff, in press; Trommsdorff 1995; Trommsdorff in press a, b, c; Trommsdorff and Kornadt 2003).

Cultural values constitute an essential part of the developmental niche; they organize the developmental path of the child and influence the belief system and value orientation of those individuals interacting with the developing child. the caretaker's child-rearing goals, beliefs, and practices, as well as the parent-child relationship, are especially important. Some of the caretaker's beliefs are related to more or less diffuse and general values, while other beliefs are more related to specific value orientations that guide individual and interpersonal behaviour.

On the other hand, individual values can affect cultural values on the basis of individual behaviour and related consequences for the primate 
and distal developmental contexts which, according to Bronfenbrenner (1977) have to be seen as an interrelated eco-system (e.g., the parentchild relation; family structure, educational and political system). Culture is based on social interactions in and outside the family, and cultural values are transmitted from one generation to the next by socialization processes. Therefore values of children and the family, as well as intergenerational relations, are important aspects of such interrelated processes.

It can be assumed that these values are part of the developmental niche and of conditions for individual development. These values can also be assumed to influence individual behaviour, such as giving birth to a child or not, whether and why children are valued, which values underlie child-rearing goals, practices, and parent-child relationships, and which values are transmitted by which means to the next generation. The respective values of children and the family will influence child-rearing practices, e.g., fostering certain value orientations and competences in the child, which in turn will influence the developmental niche and the related cultural values. Therefore, values of children and family are seen here as related to the general cultural context on the one hand, and to the individual socialization experiences including past and present parentchild relationships (see figure 1) on the other.

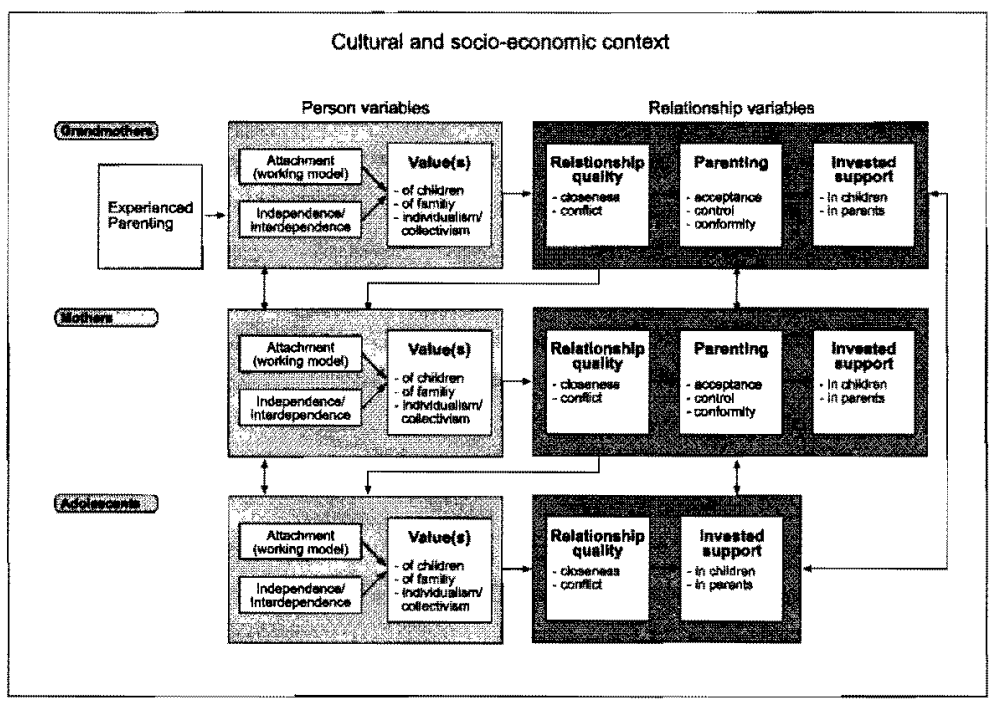

Figure 1: Parent-child relations in three generations

Accordingly, individual development, parent-child relationships, and culture are seen here as mutually related in a process in which specific values become prominent and influential for the person and for the cul- 
tural meaning system. The cultural meaning system can be seen as filtering the transmission of values. The transmission of culture is a part of 'meaning making'. The cultural meaning system gives a certain meaning to certain values (e.g., individualism, independence, collectivism, interdependence) in such a way that their transmission and psychological function for development may differ among cultures.

One important condition for the transmission of cultural values to the next generation is the quality of the parent-child relationship, which again is assumed to be affected by the cultural context and the value of children and the family (Trommsdorff 2001, in press b, c) (see figure 1). In the following discussion on the relationship between culture and individual values, we will therefore focus on the parent-child relationship as a transmission belt for cultural values. This focus is of high relevance due to the ongoing dramatic socio-demographic changes all over the world.

In the following we will present some obvious reasons for intensifying the study of value of children and the family by including the parentchild relationship in different cultures. We will therefore first refer to the observations of significant socio-demographic changes and related problems for cultures and individual development.

\section{Sociodemographic Changes}

A dramatic demographic transition can presently be observed worldwide. These changes imply changes both in the context for individual development and in developmental outcomes, including individual value orientations. Increasing longevity and declining fertility underlie the explosion in the number of older people and the drastic decline of the birth rate in many countries. Recent statistics by the United Nations show that at least 9.3 billion people will populate the earth in the year 2050 . This means an increase of more than $50 \%$ of the total population of today. Ninety-nine percent of the increase will occur in less developed countries. Only six countries share the responsibility for the increasing birth rate: The population increase in India is about $21 \%$, in China about $12 \%$, and in Pakistan, Nigeria, Bangladesh, and Indonesia the increase is about $5 \%$ in each. In general, the population in the third world will increase dramatically even if the birth rate in these countries decreases and the death rate due to AIDS is not taken into account. Otherwise, an increase to about 12 billion is to be expected.

In contrast, the demographic situation in the industrialized regions (altogether about 1.2 billion people) is quite different. A decrease in birth 
rate is presently confined to European countries and Japan. This decrease implies a decline of the total population in these countries 50 years from now: The United Nations estimates a decrease in population of the 15 countries of the European Union of about $10 \%$; that means about 40 million people fewer than today will live in the EU. More dramatically, in Japan and in Germany the decline is about $14 \%$, in Italy and Hungary about $25 \%$, and in Russia, Georgia, and the Ukraine about 28 to $40 \%$.

The general population growth and its effects on consumption of finite natural resources has recently been described as the most urgent problem for the global ecosystem (Bandura 2002). The combination of high fertility rates in poor countries, low fertility in some parts of the world, and increased global longevity contribute to risking ecologically sustainable development. Both physical and social ecology are endangered by factors accompanying population growth, such as mass migration to urban areas. This is a condition for the increase of slum settlements and related unemployment, poverty, and risky health conditions. These factors contribute to undermining socio-economic development and growth.

These demographic changes create a variety of problems. One resulting problem is how to feed and educate the increasing number of newborn children in those parts of the world which typically belong to impoverished countries, countries that need substantial economic and other support to fulfill these obligations. Another resulting problem is how to take care of the increasing number of elderly who face longevity and who often do not have the necessary financial, social, and emotional resources. In some societies the elderly can rely almost entirely on the family; in other countries, the social welfare system takes care of the medical and economic needs of the elderly. Thus, one can assume that different cultural contexts provide different answers to these demographic problems.

For more than a century, a change toward longevity has been observed all over the world. In 2005, $10 \%$ of the global population was 60 years and older. In the year 2050 , the number will increase up to $22 \%$ worldwide (United Nations. Department of Economic and Social Affairs. Population Division, 2005). In Japan and Germany (also in the U.S. and Spain) over $15 \%$ of the population is above the age of 65 . This fact of ageing societies is not confined to industrialized countries. In a short while, the number of people older than 60 years will increase in the developing countries from about $8 \%$ of the population to $20 \%$. The age of sixty will be reached by $17 \%$ of the Indian population in the year 2025 . In Japan, the average life expectancy is 86 years for women, and 77 years for men. The increase of the elderly population in the last decade has 
been $129 \%$ in Japan and 50 to $60 \%$ in other Western countries. To give an example, in Germany and in other European countries, one child is matched by two senior people. Increasing longevity is related to changes on different levels of societies, e.g., the European welfare systems is currently experiencing increasing problems because of expenses for health care and other services for aged people.

These demographic changes consist of shifts in population growth rates and in the age structure of populations (differential fertility: low in industrialized and high in developing countries), as well as increasing average worldwide longevity in less developed countries and greater increases in highly industrialized ones. These demographic changes are a result of both value changes and changes in economic and technological development. How these dramatic changes will affect individual development and value orientations is yet unclear. In the following I will discuss whether these demographic changes are related to cultural values and to values of children and family.

\section{Cultural Differences in the Value of Children}

\section{The Original Value of Children Study}

More than 30 years ago, socio-demographic research attempted to explain the increasing birth rate in many regions of the world; currently the question is how to explain the dramatic decline in fertility. More than 30 years ago, economists and demographers started a large international study on the "Value of Children" (VOC) (Arnold et al. 1975; Fawcett 1977). The main goal was to find out the reasons why young couples or parents want (or do not want) children. Thus, both the positive and negative value of children was of interest for the study. The original "Value of Children" (VOC) study was designed to explain to what degree economic factors were related to fertility.

The empirical results showed that parents mainly preferred economic, social, and emotional reasons as the value of children. The next question was whether and how far such values were related to the economic and social structure, and furthermore, whether these values predict fertility rates. The underlying hypothesis for the further study was that an economic and socio-normative value of children in contrast to an emotional value of children was related to high fertility and son preference. The results from different cultures are in line with this hypothesis. Results from the original VOC study have clearly demonstrated differences 
among countries with higher and lower economic status with respect to the preference of emotional versus economic/social values of children (Arnold et al. 1975; Fawcett 1977).

\section{Theoretical and Empirical Extensions of the VOC Study}

\section{Analysis of Psychological Variables.}

The previously economic approach to fertility and family size had to be expanded to include psychological variables. The interest shifted to additional theoretically relevant variables such as family structure, individual values, and caretaking (Kagitcibasi 1982, 1996). Empirical results of these studies showed that in traditional cultures where agriculture is the normal economic basis as compared to urban and more modernized areas, fertility was high. In these cultures, the economic and social values of children prevailed; this included the expectation that children will be of economic utility and will help their aged parents in the future (children as old-age security). In contrast, in urban areas the emotional value of children was more preferred, and the fertility rate was relatively lower. In traditional agrarian regions, sons were preferred as part of the traditional value of children, and parenting was based more on strictness and control. The results from these studies were in line with the general assumption that economic conditions influence fertility. However, these studies go beyond the assumption of a simple unidirectional causality by including the value of children as a mediating variable (Kagitcibasi 1996).

\section{Family Model Approach}

In her theory on family models, Kagitcibasi $(1996,2005$ b) integrated findings from this and further studies to explain changes in the value of children and the family as being related to modernization. The author has suggested family models of independence and interdependence that differ with respect to the preference for emotional as compared to traditional (economic and social) values of children, family size, gender equality, and parenting. According to this theoretical approach, both family models undergo changes by accommodating each other's characteristics. The family model of interdependence is assumed to change by including aspects of the independent model while still remaining different with respect to the preference of relatedness as the basis for individual development; this is in contrast to the family model of independence where the preference for autonomy is the basis for individual development (for a review on the relation between relatedness and autonomy see Kagitcibasi 2005a). 


\section{A Social Change and Multigenerational Approach}

Theoretical and empirical extensions of the original VOC study were introduced recently by a partial replication of the previous study, including some of the same countries in order to measure effects of economic, social, and value changes (Trommsdorff and Nauck 2005a, b). First results from this revised study on changes in values demonstrate the increased importance of the emotional value of children and decreased importance in the economic value of children in most countries over the last three decades (Makoshi and Trommsdorff 2002; Nauck 2000; Trommsdorff, Zheng, and Tardif 2002). However, the emotional value of children is still less and the economic value is more important in regions with low economic status (for the People's Republic of China, see Trommsdorff, Zheng, and Tardif 2002; for Turkey, see Kagitcibasi 1996; Kagitcibasi and Ataca 2005; for the Republic of Korea, see Kim, Park, Kwon, and Koo 2005; for several countries see Nauck 2005; Mayer and Trommsdorff 2005).

In the original Value of Children Study, the value of children was seen as the most important factor in explaining fertility. Other aspects such as intergenerational relationships were not taken into account. This is surprising since the quality of intergenerational relationships can be assumed to be associated to the value of children and the family, and also can be assumed to be of major importance for predicting the transmission of cultural values (see figure 1) (Trommsdorff 2001). Questions related to social change can be more precisely answered by studying intergenerational relationships. On the one hand, the quality of intergenerational relations can influence social change, e.g., by changing the role of the family and family solidarity. On the other hand, it can also be affected by socio-economic and demographic changes, including increasing longevity and a related gender gap in life expectancy, decreasing fertility, increasing postponement of first childbirth, decreasing family stability, and increasing diversity of family structure (due to divorce, single-parent families, second or third marriage, changing gender roles) (cf. Bengtson 2001; Trommsdorff and Nauck 2005 a, b; Zarit and Eggebeen 2002). However, increasing divorce rates, the increasing number of children living with stepfathers or stepmothers, or living in single-parent families have not negatively affected family solidarity in North America (Bengtson 2001).

One obvious psychologically relevant consequence of longevity on parent-child relationships in current affluent societies is the increase in joint lifetimes. Until the end of the $19^{\text {th }}$ century, personal contact with grandparents in middle childhood was an exception. In Germany, mothers born in 1875 had a mean joint lifetime of 42 years with their children; 
this has increased to almost 58 years for those born in 1940 . The joint lifetime of grandparents and grandchildren has changed accordingly (Klein and Nauck 2005). Longevity means an extended lifetime for intergenerational relationships: ageing parents can expect to share an increasing number of years with their own parents and also with their children, far beyond their adolescence and even into their children's retirement. Due to increased longevity, intergenerational relationships can persist through an increasing number of years of the life span.

Different aspects of intergenerational relationships have to be taken into account when studying their associations with values in different cultures. Intergenerational relations can exist between grandparents and grandchildren, between adult children and their ageing parents, and between parents and their children. The relationship quality may be analyzed according to emotional closeness, solidarity between the generations, patterns of intergenerational exchanges and support, family eldercare, the continuity or discontinuity of intergenerational relations over time, and similarities and differences between the generations with respect to values (e.g., Bengtson and Robertson 1985; Cooney 1997; King and Elder 1997; Trommsdorff in press b, c; Zarrit and Eggeben 2002).

\section{The Cross-Cultural Study on Value of Children and Intergenerational Relations}

So far, there is little empirical evidence of the ongoing sociodemographic changes in different cultures and their associations with the value of children, the family, and parent-child relationships. Therefore, we initiated a large cross-cultural study (e.g., Nauck 2005; Trommsdorff 2001; Trommsdorff and Nauck 2005a; b). This study is a partial replication and extension of the original "Value of Children" study (Arnold and Fawcett 1975; Fawcett 1973).

\section{Theoretical Frame and Research Goals}

The present cross-cultural study aims to go beyond questions of fertility and takes into account cultural and individual values, family structure, parenting, and intergenerational relations; thereby it suggests a major theoretical revision of the former explanatory model (see reports on eight countries in Trommsdorff and Nauck 2005b). One question is whether ongoing socio-demographic changes (e.g., longevity and decline of high fertility rates) are related to value orientations and intergenerational relationships in different countries. 
We have mentioned before that increasing longevity is a worldwide phenomenon that also includes developing countries. Due to the world-wide increase in longevity, parents and their children will, in general, share on average almost five decades as adults. However, the effects of an increasing length of overlapping lifetime on the quality of the parent-child relationships beyond childhood and adolescence and on intergenerational relations and cultural transmission are not yet known. Therefore, we are especially interested in studying this relationship over the lifespan in different cultures (Trommsdorff in press $b, c$ ).

One hypothesis is that the culture-specific structure of intergenerational relations, its components, and influential factors are associated with different cultural values, including the value of interdependence and filial piety as a basis for parent-child relations in East Asian cultures in contrast to the value of individualism and independence in Western cultures (see Chao 1994; Ho 1986; Rothbaum and Trommsdorff in press; Trommsdorff and Kornadt 2003). Cultural values (regarding the family and children) are assumed to be related to specific socialization experiences (including attachment and parenting) and the quality of the parentchild relationship over the lifespan (see figure 1).

The present study thus can be seen as a quasi experimental approach to the study of the cultural meaning system: most countries face the problem of dramatic socio-demographic changes. How they will cope with this problem depends on their respective cultural meaning systems, which affect the parent-child relationship and the transmission of values. In the following, we focus on individual values and on aspects of the parent-child relationship.

\section{Individual Values (General and Specific)}

Individualism (idiocentrism) in contrast to collectivism (allocentrism) is usually understood as encompassing a preference for self-assertion, more distant and detached social behaviour, autonomy, competition and conflict, egalitarian relationships, privacy and solitude, preference for temporary relationships, and low in-group versus out-group differentiation (Hofstede, in press; Triandis 1995). The differentiation between the independent in contrast to the interdependent self was introduced by Markus and Kitayama (1991). The independent self is usually understood as separate from the social context and as striving for autonomy and selfassurance; the interdependent self is usually understood as being closely related to members of the family and the in-group; accordingly, the individual experience is the self in relation to others. The model of the interdependent self is to fit in with others, to fulfil social obligations, and engage in harmonious interpersonal relationships. The interdependent self 
is related to high importance of family values (have good relationships with one's relatives, feel close with one's family members, feel responsible for family members' well-being) (Georgas et al. 2001). The values of individualism and independence, as compared to collectivism and interdependence, have different implications for developmental goals and outcomes (e.g., Greenfield et al. 2003; Rothbaum et al. 2000; Rothbaum and Trommsdorff in press).

Much research has been carried out to demonstrate differences in the preference of independence and interdependence as compared to collectivism and interdependence in North American (or European) as compared to Asian (or African) countries, with higher scores on individualism and independence in North American people. In contrast, research on the value of children is rare.

The value of children in the original Value of Children (VOC) model (Arnold et al. 1975) was conceptualized in terms of positive and negative values of children and the value in having a large or a small family. Positive values include emotional benefits, economic benefits and security, self-enrichment and development, identification with children, and family cohesiveness and continuity. Negative values include emotional and economic costs, restrictions or opportunity costs, physical demands, and family costs. The emotional value of children (emotional benefits and self-enrichment) has been studied in contrast to the economic and practical, social, or religious value of children as part of the model in order to predict fertility and family planning.

\section{Parent-Child Relationship}

At present, there is a lack of research integrating general or specific values assumptions with values of children and the family, and to also take into account the parent-child relationship in different cultures. Rothbaum, Pott et al. (2000) have suggested that different patterns of parent-child relationships in Western and non-Western countries (e.g., Japan and the U.S.) are related to different cultural models of an individualistic and a social orientation. These patterns are assumed to be based on different needs: the need for separation or closeness, for independence or interdependence, and for autonomy or relatedness.

The individualistic pattern is described by the value of 'generative tension', which is based on the concern to establish and maintain independence and to fulfill individual goals. Here, parent-child relations are characterized by independence and partnership, acceptance of conflicts, and negotiations of individual interests. The social-oriented pattern is characterized by the cultural value of 'symbiotic harmony', which is based on the concern to maintain interdependence by fulfilling one's du- 
ties and obligations, and to meet social expectations. Therefore, children's obedience, filial piety, their compliance with their parents' expectations, their life-long duties, and obligations in honor of the parents, are highly valued. Such interdependent parent-child relationships are characterized by harmony, cooperation, and the obligation to 'reciprocate'. The authors are less interested in describing differences in the importance and strength than in differences in the meaning and dynamics of parent-child relationships.

This theoretical approach to parent-child relationships is empirically validated by several studies (for an overview see Trommsdorff, in press $a, b, c)$. In Westem countries, parent-child relationships are characterized by a need for independence which can be related to conflicts but also to mutual support. Support is usually related to an emotionally close relationship. In Asian countries, children's and parents' behavior is part of a stable relationship of mutual obligation, based on emotional interdependence as indicated by the concepts of filial piety and reciprocity (e.g., Kim, Kim, and Hurh 1991; Schwarz, Trommsdorff, Kim, and Park, in press; Wang and Hsueh 2000). Asian adolescents prefer values of deference, obligation and respect for their parent and family elders in contrast to their European and American peers (Ying, Coombs, and Lee 1999). The adult children feel obliged to their parents; they are aware of their parents' and especially their mothers' sacrifices. In line with the Confucian values of seniority and filial piety, aging parents have high ranking positions in the family and are often regarded as the 'honorable elders' (Palmore and Maeda 1985; Wang and Hsueh 2000). The filial piety is seen less as fulfilling a formal duty but rather as an emotional solidarity which is also related to the shared belief in ancestors and the continuity of the family. This family orientation is part of cultural transmission and continuity in most Asian cultures.

\section{Samples}

We included countries that differ in cultural values, socio-demographic variables (fertility and longevity), socio-economic conditions (industrialization, urbanization), religious orientation, and political system. For example, Germany, is a Western highly industrialized, democratic, individualistic country with declining fertility rates; Republic of Korea is a society in transition with rather stable and low fertility rates and Confucian value orientations; The People's Republic of China is a rapidly changing country with strong differences between urbanized and rural areas, a long history of Confucian value orientation and family structure, high population growth, presently advocating the one-child policy; Indonesia is a still traditional mainly agrarian country with Islamic religious 
background, high fertility, and a strong family orientation (for more extensive descriptions of the countries included in the VOC study see Trommsdorff and Nauck 2005a, b). So far, the countries included in our VOC study are Germany, France, Turkey, Israel, Palestine, Indonesia, Republic of Korea, The People's Republic of China, India, and South Africa. Some of these countries have participated in the original VOC study (Turkey, Indonesia, and the Republic of Korea). Data from those samples can be compared with the results from the original VOC study in order to assess social, economic, and value changes. In each country, we have chosen samples of three (biologically related) generations (belonging to one family: grandmothers, mothers, adolescents) (300 families in each country) plus a sample of young mothers with a preschool-child (300 in each country) (altogether 1000 persons in each country).

\section{Procedures and Instruments}

All participants were interviewed based on a standardized interview which was the result of pilot studies in cooperation with the team members from the different countries. We used instruments validated in various cultures for assessing general and specific value orientations (such as individualism, collectivism; independence, interdependence; family orientation; social-economic and emotional value of children), parenting (warmth and control), the quality of the intergenerational relations (attachment; communication quality, e.g., intimacy, conflict; and support, e.g., instrumental, emotional, and prospective future support given to the aging parents) (for a detailed description of the instruments see Schwarz, Chakkarath, Trommsdorff, Schwenk, and Nauck 2001).

\section{Empirical Results of the Revised VOC and Intergenerational Relations Study}

In the following we will focus on the cultural meaning system when reporting on first empirical results on the values and parent-child relationships. We will discuss the results within the theoretical framework of the cultural model of independence and interdependence (e.g., Markus and Kitayama 1991; Greenfield et al. 2003; Kagitcibasi 2005 a, b; Rothbaum et al. 2000; Rothbaum and Trommsdorff, in press; Trommsdorff in press, $a, b, c)$.

\section{Parent-Child Relationship}

One aspect of the parent-child relationship is the quality of communication and the mutual subjective perception of the relationship quality. In 
one of our studies comparing German and Indonesian samples of grandmothers and their adult daughters (mothers) we found that low self disclosure ('intimacy') of Indonesian mothers of adult daughters was related to their collectivistic value orientation (Schwarz and Trommsdorff, in press). This result is not surprising when taking into account that in a social-oriented culture like Indonesia, mutual understanding as part of the relationship quality is not necessarily based on verbal exchange of personal needs and wishes but rather on an empathic feeling with the other. Empathy is an essential part of the interdependent self and characteristic for the cultural model of interdependence (Markus and Kitayama 2001). The results from our study thus are in line with assumption that collectivistic values are associated with the preference for empathy in case of an interdependent parent-child relationship.

\section{Value of Children}

The cultural model of interdependence has consequences for another aspect of parent-child relationships, the value of children and the willingness of children to give support to their parents. Children's providing support to their aging parents (as part of old age security) is an important economic value of children in traditional agrarian countries as our own studies on the value of children (VOC) in different countries demonstrate (Nauck 2000; Mishra et al. 2005; Mayer and Trommsdorff 2005; Trommsdorff, Zheng, and Tardif 2002; Trommsdorff and Nauck 2005, a, b). This is in line with the previous studies on the value of children (Kagitcibasi 1982; 1996). With modernization, the economic-utilitarian value of children has declined; raising children has become more expensive, and old-age security is usually provided by social security and welfare systems. This has contributed to the decline of fertility.

However, is the economic value of children the only reason for giving birth to a child? As Kagitcibasi $(1982 ; 1996)$ has pointed out there are other needs to be fulfilled when having a child such as the emotional value of the child which, however, is related to lower fertility (one does not need to have many children to experience emotional satisfaction). While the previous studies on the VOC have usually pointed out to the difference between the economic and the emotional value of children in traditional versus modernized countries, in our own cross-cultural studies it was obvious that the emotional value of children is generally important even in those countries where the social-economic value of children is high (Mayer and Trommsdorff 2005). The economic value of children is still high in traditional agrarian countries such as India, Indonesia, and South Africa; it is less important in China, Israel, Turkey, and the Republic of Korea; and it is nearly not important in Germany. In our further 
analyses on the relations between the value of children and planned fertility of adolescents from different countries we found that we have to differentiate between predictions on the cultural and on the individual level. These results are based on multi-level analyses of individual and cultural effects on the planned number of children. On the cultural level, the economic value of children was positively related, and the emotional value of children was negatively related to planned fertility. However, on the individual level, the economic value of children was unrelated, and the emotional value of children was positively related to the planned number of children (Mayer and Trommsdorff 2005). The advantage of such multi-level analyses is to clarify differential effects on the cultural and the individual level. The empirical results stimulate the need to clarify whether the function of the emotional value of children differs in traditional and modernized cultures. Accordingly, the question of the cultural meaning of the value of children arises. It may well be that the emotional value of children is high (and of similar importance) in very different cultures but has different implications for fertility and possibly also for parent-child relationships.

\section{Parent-Child Relationship}

Therefore, we now have a brief look at some results of our study on the associations between the emotional value of the child and aspects of the parent-child relationship in different countries. In China where the economic value of the child is of medium high importance, and the one-child policy is practiced, adult daughters' emotional value of the child is significantly associated with a positive relationship to their parents (high intimacy or self-disclosure and high readiness for supporting old parents). In Indonesia, where the traditional economic value of the child is highly important, intimacy in the communication is unrelated but supporting aging parents is positively related to the emotional value of child. In Germany, were the economic value of the child is low and the emotional value of the child is high, the emotional value of the child is also significantly related to intimacy in communication (the same as in China) but not related to supporting aging parents (quite different from China and Indonesia) (Trommsdorff, unpublished data). These correlational results demonstrate different culture-specific patterns of associations between the emotional value of children and a relevant aspect of the parentchild relationship. The pattern of these results indicates that the function of the emotional value of the child for the parent-child relationship varies among cultures. This gives rise to the question whether these variations are in line with a culture-specific meaning of the value of children and 
parent-child relationships. In order to pursue this question, we will discuss some further results of our study.

\section{Supporting Aging Parents}

Giving support to aging parents can be seen as an important behavioral aspect of parent-child relationships (Trommsdorff, in press, $b, c$ ) and as an essential element of family solidarity which is especially relevant in societies with growing longevity and need for social security of the aging population (Bengtson, 2001). In line with our hypothesis, in our East Asian and Western samples, a high importance of family values was associated with more support-oriented intergenerational relationships (e.g., in Indonesia and in India as compared to Germany) (Albert, Trommsdorff, Mayer, and Schwarz 2005; Mishra, Mayer, Trommsdorff, Albert, and Schwarz 2005).

In further studies we tested whether other aspects of the parent-child relationship (self-disclosure in communication) are associated with giving emotional and instrumental support to aging parents. We found a clear pattern of positive associations in all cultures (Trommsdorff, unpublished data). At first sight, these results indicate cross-cultural similarities. However, we should be careful not to be mislead by this simple view. We have reason to assume that self-disclosure and support each have a different meaning in Western and East Asian cultures as indicated above. High self-disclosure may be related to support in Westem cultures since this kind of communication usually indicates a positive relationship which in turn increases the altruistic prosocial motivation to give support. However, in East Asian cultures, high self-disclosure may rather indicate a low relationship quality since a high relationship quality in these cultures is characterized by empathy and refraining from the expression of own needs and wishes through self-disclosure (see above, Trommsdorff and Schwarz, in press). Giving support under such circumstances is based less on an altruistic prosocial motivation but rather on a normative prosocial motivation.

When looking at conflict as another aspect of the communication quality, no significant association with instrumental or emotional support occurs for the German sample however, a significantly positive association occurs for the Korean and the Indonesian samples. Taking into account the cultural meaning of conflict in parent-child relationships, these results are of special interest since they indicate that even though conflict is quite rare in Asian in contrast to the Western cultures, conflict does not undermine giving support to parents in Asian samples; also giving support to parents does not reduce potential conflict in the relationship. The life-long obligation to honor and support one's parents is a dominant 
norm which regulates parent-child relationships in case of being socialized according to an interdependent cultural model.

This interpretation shows that cultural similarities in the pattern of results (associations) may hide culture-specificities in the underlying individual motivation. Therefore, further analyses are necessary to clarify whether or not culture-specific functional relations are underlying seemingly cultural similarities. Such further analyses may consist in taking into account other theoretically relevant variables which allow to clarify the cultural meaning of the results. Giving support to the parents can be based on different motivations. A differentiation between an altruistie and a norm-oriented motivation seems to be useful when studying the cultural meaning of the parent-child relationship and giving support to parents (Trommsdorff, a, c).

In the following we will ask whether different motivations for giving support are related to differences in the cultural meaning of 'reciprocity'. Reciprocity in Western theorizing is usually understood as the balanced give and take in interpersonal relationships. We doubt that this meaning of reciprocity is the same in non-Western cultures where the cultural model of interdependence prevails. Therefore our further analyses deal with the question whether the relationship quality is affected by the subjective perception of a balanced give and take between the adult daughter and the elderly mother, and whether cultural values play a role. A comparison of German and Indonesian samples clearly showed that the Indonesian as compared to the German adult daughters do not mind to give more than they receive (Schwarz, Trommsdorff, Kim and Park, in press). Obviously, traditional values of filial piety and supporting one's parents is accepted as a life-long obligation in Indonesia. Thus, different cultural meanings of the communication quality and of reciprocity are to be taken into account when studying parent-child relationships over the life span.

Further results from Korean, Chinese and German samples of grandmothers and their adult daughters (mothers) confirm the hypothesis of the culture-specific meaning of parent-child relationships (Schwarz and Trommsdorff, in press). When the cultural model of interdependence prevails, the readiness to give support is high. This is independent of the support received in the parent-child relationship as can be shown from the results of the Korean and Chinese samples. In contrast, when the cultural model of independence prevails, the readiness for supporting one's aging parents depends on the 'rational' norm of reciprocity, that is the perceived balance of received and given support; this is the case for the German sample.

In these Asian countries, the value of filial piety underlie the child's life-long obligation to give (unconditional) support to the parents. Here, 
the readiness for support is not based on the rational norm of reciprocity with checking the balance of how much support one has received from the parents or how much support one has already given to the parents. Rather, the readiness to support one's parents is based on the deep-rooted feeling of life-long interdependence and of the obligation to give (unconditional) support to one's parents. Giving support in parent-child relationships in different countries is therefore based on different conceptions and cultural meanings of 'reciprocity'.

Past experience of non-balanced support in East Asian countries does not affect adult daughters' willingness to support their parents in contrast to German daughters; German adult daughters rather give support to their parents in line with the norm of reciprocity which is based on calculating the balance of give and take. German adult daughters also give (instrumental and emotional) support to their parents in case of favoring an interdependent self (Trommsdorff, unpublished data). These results are in line with the view that the cultural model of independence or interdependence can predict whether and why adult children support their aging parents.

\section{Transmission of Values}

As suggested in our model of intergenerational relations over the life span (Trommsdorff 2001 ; in press b, c), the relationship quality between mothers and adolescent children should influence the extent of transmission. According to the two-step model by Grusec and Goodnow (1994) (pointing out to the function of the accurate perception and acceptance of parental values by children) it was assumed here that intimacy in the relationship and perceived acceptance enhances the communication between adolescents and their mothers and thereby increases the accurate perception and the acceptance of maternal values. Therefore, we tested the (moderating) effects of the parent-child relationship on the transmission of values (general and domain-specific values like individualism/collectivism, value of family and interdependence) for a German sample of mothers and their adolescent children by regression analyses (Albert and Trommsdorff 2003, August). The results showed that all four value orientations of the adolescents were predicted by the value orientations of mothers. The prediction of individualism, however, was relatively weak, indicating a rather selective transmission of values. Mean values of mothers and adolescents on all scales differed indicating a relative as opposed to an absolute transmission. Apart from this, intimacy and felt acceptance by parents turned out to be successful transmission belts for values of collectivism and the value of the family, but not for individualism and interdependence. Furthermore, all aspects of the rela- 
tionship quality had direct effects on the value orientations of the adolescents. These results support the assumption that the relationship quality has an important impact on the development of value orientations of adolescents beyond its role as a moderator.

In further studies, we tested the model of transmission of values in cross-cultural comparison by analyzing the role of controlling parenting for the transmission of various values in Germany and France, two individualistic countries with different values of the family and of children (Albert, Trommsdorff, and Sabatier 2005). In both countries, significant associations between the preference of collectivistic values and controlling parenting occurred; moreover, in France the value of the family and controlling parenting were significantly associated. Regression analyses showed that parental control explains the successful transmission of collectivistic values in the German sample and the successful transmission of family values in the French sample. These results indicate the culturespecific function of both, parenting (as one aspect of parent-child relationships) and value orientations for the transmission of values. This study also underlines the necessity to test the functional equivalence of aspects of parent-child relationships in different cultures in order to gain a better understanding of the respective cultural meaning systems.

\section{Conclusion and Outlook}

One major aim of this chapter was to analyse associations between values and parent-child relationships over the life-span by taking into account parenting and the transmission of values in different cultures. The presently ongoing study on "Value of Children and Intergenerational Relationships" will tell us more about cultural differences and similarities in the associations between values and parent-child relationships by taking into account the cultural meaning systems.

Culture has been understood here as a complex meaning system interrelated with socio-demographic, and economic conditions, and penetrating all spheres of economic, social, and individual processes. The cultural meaning system has been seen here as the basis for parent-child relationships which in turn is the basis for the transmission of cultural values. The transmission of cultural values is a part of 'meaning making'. Thus the cultural meaning system filters the transmission of values according to the general cultural model.

In certain cultures, the general cultural model of interdependence prevails while in other cultures the model of independence dominates. The related culture-specific values are partly internalized by caretakers 
and affect their values, beliefs, behavior, and their relationship with their children (Greenfield et al. 1993; Rothbaum and Morelli 2005; Schwarz, Schäfermeier, and Trommsdorff 2005; Trommsdorff 2001, in press a, b, c; Trommsdorff and Friedlmeier 2004; Trommsdorff and Kornadt 2003). The different means of socialization and transmission of culture in different cultural contexts with preference for the independent versus the interdependent model have been described on the basis of numerous empirical studies (e.g., Chao and Tseng 2002; Rothbaum and Trommsdorff in press; Rothbaum, Weisz et al. 2000; Stevenson and Zusho 2002; Trommsdorff and Kornadt 2003).

According to these general cultural models and the related culturespecific meaning systems, quite different qualities of intergenerational relationships develop which in turn affect the intergenerational cultural transmission. Our results have shown that the quality, and the function of the parent-child relationships can be more adequately described when taking into account the cultural meaning of the relationship, and the individual value orientations e.g., the value of the child and the family (Rothbaum, Weisz, Pott, Miyake, and Morelli 2000; Trommsdorff, in press $b, c)$. For example, we have shown that communication, support, and reciprocity have a very different cultural meaning in East Asian as compared to Western countries, depending on the cultural model of independence and interdependence.

A shortcoming of our study certainly is that we are still too much speculating about the cultural meaning system without providing sufficient empirically tested evidence. Therefore, further research is needed to empirically assess the cultural meaning, e.g., by relating data from the cultural and the individual level. This can be methodologically solved by multi-level analyses including a larger number of cultures overcoming a shortcoming of most cross-cultural research with the focus on only a limited number of cultures. Further cross-cultural studies on the cultural meaning system should be carried out on both, the level of cultures and on the individual level, relating the cultural and the individual level in a systematic way. For example, the above mentioned socio-demographic changes on the country level point to a new role of grandparents and to corresponding effects on the parent-child relationship on the individual level in different generations.

Rapidly changing cultural contexts may be related to a reversal in the direction of the transmission of cultural values. Intergenerational relations will be of special interest for the study whether and how a transmission of cultural values takes place from the younger to the older generation, and how this affects the intergenerational relations and future sociocultural change. Results from our studies actually point to more similari- 
ties among German grandparents and adolescent grandchildren than among grandparents and their adult children (Trommsdorff, Mayer, and Albert 2004). Adolescent children may initiate changes in the values, beliefs and behavior of their parents who in turn develop value orientations which become increasingly different from the value orientations of their elderly parents (grandparents). However, even such studies will be of little theoretical value when neglecting cultural factors.

Since a systematic study of intergenerational relationships in different cultures is still missing, we have started our project on the "Value of Children (VOC) and Intergenerational Relations" (Trommsdorff and Nauck, in press, a). This study will take into account possible socioeconomic, socio-demographic and cultural changes and overcome a shortcoming of most studies on parent-child relationships with the focus on adjacent generations. The present study thus can be seen as a quasiexperimental approach to the study of the cultural meaning system: Most countries face the problem of dramatic socio-demographic changes. How they will cope with this problem depends on their respective cultural meaning systems which affect the parent-child relationship and the transmission of values. Accordingly, the cultural meaning of parent-child relationships needs to be theoretically and empirically clarified in order to improve our understanding of developmental outcomes, including the transmission of values from a multi-generational and life-span developmental view.

The goal of the present chapter has been to point out that psychological research will systematically increase its theoretical contribution when taking into account the cultural meaning of the methods used and the empirical results. Our study has shown that the value of the child and the family and its associations with parent-child relationships can be better understood when taking into account their respective functional meaning in the cultural context.

\section{References}

Albert, I./Trommsdorff, G. (2003, August). Intergenerational Transmission of Family Values. Poster presented at the $\mathrm{XI}^{\text {th }}$ European Conference on Developmental Psychology in Milan, Italy.

Albert, I./Trommsdorff, G./Mayer, B./Schwarz, B. (2005). Value of Children in Urban and Rural Indonesia: Socio-Demographic Indicators, Cultural Aspects and Empirical Findings. In: G. Trommsdorff/B. Nauck (Eds.). The Value of Children in Cross-Cultural Per- 
spective. Case Studies from Eight Societies (pp. 171-207). Lengerich, Germany: Pabst Science.

Albert, I./Trommsdorff, G./Sabatier, C. (2005, July). Parenting and Intergenerational Transmission of Values in Germany and France. Paper presented at the $7^{\text {th }}$ European Regional Congress of the International Association for Cross-Cultural Psychology 'New Scenarios for Cultural Interaction', San Sebastian, Spain.

Arnold, F./Bulatao, R.A./Buripakdi, C./Chung, B.J.Fawcett, J.T./ Iritani, T., et al. (1975). The Value of Children: A Cross-National Study, Vol. I. Introduction and Comparative Analysis. Honolulu, HI: East-West Population Institute.

Arnold, F.Fawcett, J.T. (1975). The Value of Children, Vol. 3. Hawaii. Honolulu, HI: East-West Center.

Bandura, A. (2002). Environmental Sustainability by Sociocognitive Deceleration of Population Growth. In: P. Schmuch/W. Schultz (Eds.). The Psychology of Sustainable Development (pp. 209-238). Dordrecht, The Netherlands: Kluwer.

Bengtson, V.L. (2001). Beyond the Nuclear Family: The Increasing Importance of Multigenerational Bonds. In: Journal of Marriage \& Family, 63, 1-16.

Bengtson, V.L./Robertson, J.F. (Eds.). (1985). Grandparenthood. Beverly Hills, CA: Sage Publications.

Berry, J. W./Poortinga, Y. H./Segall, M. H./Dasen, P. R. (1992). CrossCultural Psychology: Research and Applications. New York: Cambridge University Press.

Berry, J.W./Poortinga, Y.H./Segall, M.H./Dasen, P.R. (2002). CrossCultural Psychology: Research and Applications, Vol. 2. New York: Cambridge University Press.

Boesch, E.E. (1991). Symbolic Action Theory and Cultural Psychology. Heidelberg: Springer.

Bronfenbrenner, U. (1977). Toward an Experimental Ecology of Human Development. In: American Psychologist, 32, 513-531.

Bruner, J. S. (1990). Culture and Human Development: A New Look. In: Human Development, 33, 344-355.

Bruner, J.S. (1996). Acts of Meaning. Cambridge, MA.: Harvard University Press.

Chao, R.K. (1994). Beyond Parental Control and Authoritarian Parenting Style: Understanding Chinese Parenting Through the Cultural Notion of Training. In: Child Development, 65, 1111-1119.

Chao, R./Tseng, V. (2002). Parenting of Asians. In: M.H. Bornstein (Ed.). Handbook of Parenting, Vol. 4. Social Conditions and Applied parenting ( $2^{\text {nd }}$ ed., pp. 59-93). Mahwah, NJ: Erlbaum. 
Cooney, T.M. (1997). Parent-Child Relations Across Adulthood. In: S. Duck (Ed.). Handbook of Personal Relationships ( $2^{\text {nd }}$ ed., pp. 451468). Chichester, UK: Wiley.

Ehrlich, P.A./Ehrlich, A.H./Daily, G.C. (1995). The Stork and the Plow: The Equity Answer to the Human Dilemma. New York: Putnam's.

Fawcett, J.T. (1977). The Value and Cost of Children: Converging Theory and Research. In: L.T. Ruzicka (Ed.). The Economic and Social Supports for High Fertility (Vol. 2, pp. 91-114). Canberra, Australia: Department of Demography.

Fawcett, J.T. (Ed.). (1973). Psychological Perspectives on Population. New York: Basic Books.

Georgas, J./Bafiti, T./Poortinga, Y.H./Christakopoulou, S./Kagitcibasi, C./Kwak, K., et al. (2001). Functional Relationships in the Nuclear and Extended Family: A 16-Culture Study. In: International Journal of Psychology, 36, 289-300.

Greenfield, P. M./Keller, H./Fuligni, A. J./Maynard, A. (2003). Cultural Pathways Through Universal Development. In: Annual Review of Psychology, 54, 461-490.

Grusec, J.E./Goodnow, J.J. (1994). Impact of Parental Discipline Methods on the Child's Internalization of Values: A Reconceptualization of Current Points of View. In: Developmental Psychology, 30, 4-19.

Grusec, J.E./Hastings, P. (Eds.) (in press). The Handbook of Socialization. New York: The Guilford Press.

Ho, D.Y.F. (1986). Chinese Patterns of Socialization: A Critical Review. In: M.H. Bond (Ed.). The Psychology of the Chinese people. (pp. 1-37). Hong Kong: Oxford University Press.

Hofstede, G.H. (1980). Culture's Consequences: International Differences in Work-Related Values. Beverly Hills, CA: Sage.

Hofstede, G.H. (2001). Culture's Consequences: Comparing Values, Behaviors, Institutions and Organizations Across Nations $\left(2^{\text {nd }}\right.$ ed.). Thousand Oaks, CA: Sage.

Hofstede, G.H. (in press). Der kulturelle Kontext psychologischer Prozesse [The Cultural Context of Psychological Processes]. In: G. Trommsdorff/H.-J. Komadt (Eds.). Enzyklopädie der Psychologie: Themenbereich C. Theorie und Forschung: Serie VII. Kulturvergleichende Psychologie: Band 1. Theorien und Methoden in der kulturvergleichenden und kulturpsychologischen Forschung. Göttingen, Germany: Hogrefe.

Kagitcibasi, C. (1982). The Changing Value of Children in Turkey. Honolulu, HI: East-West Center.

Kagitcibasi, C. (1996). Family and Human Development Across Cultures: A View from the Other Side. Mahwah, NJ; Erlbaum. 
Kagitcibasi, C. (2005a). Autonomy and Relatedness in Cultural Context: Implications for Self and Family. In: Journal of Cross-Cultural Psychology, 36, 403-422.

Kagitcibasi, C. (2005b). Modernization Does not mean Westernization: Emergence of a Different Pattern. In: W. Friedlmeier/P. Chakkarath/B. Schwarz (Eds.). Culture and Human Development. The Importance of Cross-Cultural Research for the Social Sciences (pp. 255-272). Hove, UK: Psychology Press.

Kagitcibasi, C./Ataca, B. (2005). Value of Children and Family Change: A Three Decade Portrait from Turkey. In: Applied Psychology: An International Review. Special Issue: Value of Children in SocioCultural Contexts, 54(3), 317-337.

Kim, K.C./Kim, S./Hurh, W.M. (1991). Filial Piety and Intergenerational Relationship in Korean Immigrant Families. In: International Journal of Aging and Human Development, 33, 233-245.

Kim, U./Park, Y.-S./Kwon, Y.-E./Koo, J. (2005). Values of Children, Parent-Child Relationships, and Social Change in Korea: Indigenous, Cultural, and Psychological Analysis. In: Applied Psychology: An International Review. Special Issue: Value of Children in Socio-Cultural Contexts, 54 (3), 338-354.

King, V./Elder, G.H. (1997). The Legacy of Grandparenting: Childhood Experiences with Grandparents and Current Involvement with Grandchildren. In: Journal of Marriage \& Family, 59, 848.

Klein, T./Nauck, B. (2005). Families in Germany. In: B.N. Adams/J. Trost (Eds.). Handbook of World Families (pp. 283-312). Thousand Oaks, CA: Sage.

Makoshi, N./Trommsdorff, G. (2002). Value of Children and MotherChild Relationships in Japan: Comparisons with Germany. In: U. Teichler/G. Trommsdorff (Eds.). Challenges of the $21^{\text {st }}$ Century in Japan and Germany (pp. 109-124). Lengerich, Germany: Pabst Science.

Markus, H.R./Kitayama, S. (1991). Culture and the Self: Implications for Cognition, Emotion, and Motivation. In: Psychological Review, 98, 224-253.

Mayer, B./Trommsdorff, G. (2005, July). Adolescents' Values and Future Orientation. Multi-Level Analyses from 11. Cultures in the Value-of-Children Study. Paper presented at the $7^{\text {th }}$ European Regional Congress of the International Association for Cross-Cultural Psychology 'New Scenarios for Cultural Interaction', San Sebastian, Spain.

Mishra, R.C./Mayer, B./Trommsdorff, G./Albert, I.,/Schwarz, B. (2005). The Value of Children in Urban and Rural India: Cultural 
Background and Empirical Results. In: G. Trommsdorff/B. Nauck (Eds.). The Value of Children in Cross-Cultural Perspective. Case Studies from Eight Societies (pp. 143-170). Lengerich, Germany: Pabst Science.

Nauck, B. (2000). Social Capital and Intergenerational Transmission of Cultural Capital within a Regional Context. In: I. Bynner/R.K. Silbereisen (Eds.). Adversity and Challenge in Life in the New Germany and in England (pp. 212-238). Houndmills, UK: Macmillan.

Nauck, B. (2005). Changing Value of Children: An Action Theory of Fertility Behavior and Intergenerational Relationships in CrossCultural Comparison. In: W. Friedlmeier/P. Chakkarath/B. Schwarz (Eds.). Culture and Human Development. The Importance of CrossCultural Research for the Social Sciences (pp. 183-202). Hove, UK: Psychology Press.

Oyserman, D./Coon, H.M./Kemmelmeier, M. (2002). Rethinking Individualism and Collectivism: Evaluation of Theoretical Assumptions and Meta-Analyses. In: Psychological Bulletin, 128, 3-72.

Palmore, E.B./Maeda, D. (1985). The Honorable Elders Revisited (Otoshiyori saikô). Durham, NC: Duke University Press.

Rothbaum, F./Morelli, G. (2005). Attachment and Culture: Bridging Relativism and Universalism. In; W. Friedlmeier/P. Chakkarath/B. Schwarz (Eds.). Culture and Human Development. The Importance of Cross-Cultural Research for the Social Sciences (pp. 99-123). Hove, UK: Psychology Press.

Rothbaum, F./Pott, M.Azuma, H./Miyake, K./Weisz, I. (2000). The Development of Close Relationships in Japan and the United States: Paths of Symbiotic Harmony and Generative Tension. In: Child Development, 71, 1121-1142.

Rothbaum, F.Trommsdorff, G. (in press). Do Roots and Wings Complement or Oppose one Another? The Socialization of Relatedness and Autonomy in Cultural Context. In: J. E. Grusec/P. Hastings (Eds.). The Handbook of Socialization. New York: The Guilford Press.

Rothbaum, F./Weisz, J./Pott, M./Miyake, K./Morelli, G. (2000). Attachment and Culture: Security in the United States and Japan. In: American Psychologist, 55, 1093-1104.

Schwartz, S.H. (1992). Universals in the Content and Structure of Values: Theoretical Advances and Empirical Tests in 20 Countries. In: M.P. Zanna (Ed.). Advances in Experimental Social Psychology (Vol. 25, pp. 1-65). San Diego, CA: Academic Press.

Schwartz, S.H. (2004). Mapping and Interpreting Cultural Differences Around the World. In: H. Vinken/J. Soeters/P. Ester (Eds.). Com- 
paring Cultures: Dimensions of Culture in a Comparative Perspective (pp. 43-73). Leiden, The Netherlands: Brill Academic Publishers.

Schwartz, S.H./Bilsky, W. (1990). Toward a Theory of the Universal Content and Structure of Values: Extensions and Cross-Cultural Replications. In: Journal of Personality \& Social Psychology, 58, 878-891.

Schwarz, B./Chakkarath, P./Trommsdorff, G./Schwenk, O./Nauck, B. (2001). Report on Selected Instruments of the Value of Children (Main study). Unpublished manuscript, University of Konstanz, Konstanz, Germany,

Schwarz, B./Schäfermeier, E./Trommsdorff, G. (2005). The Relationships Between Value Orientation, Child-Rearing Goals, and ChildRearing Behavior: A Comparison of Korean and German Mothers. In: W. Friedlmeier/P. Chakkarath/B. Schwarz (Eds.). Culture and Human Development: The Importance of Cross-Cultural Research to the Social Sciences (pp. 203-230). Hove, UK: Psychology Press.

Schwarz, B./Trommsdorff, G. (in press). Reciprocity in Intergenerational Support: A Comparison of Korean, Chinese, and German Adult Daughters, Current Sociology.

Schwarz, B./Trommsdorff, G./Kim, U./Park, Y.-S. (in press). Intergenerational Support: A Comparison of Women from the Republic of Korea and Germany. In: Current Sociology.

Stevenson, H.W./Zusho, A. (2002). Adolescence in China and Japan: Adapting to a Changing Environment. In: B.B. Brown, R.W. Larson/T. S. Saraswathi (Eds.). The World's Youth: Adolescence in Eight Regions of the Globe (pp. 141-170). Cambridge, MA: Cambridge University Press.

Super, C.M./Harkness, S. (1997). The Cultural Structuring of Child Development. In: J.W. Berry/P.R. Dasen/T.S. Saraswathi (Eds.). Handbook of Cross-Cultural Psychology, Vol. 2. Basic Processes and Human Development ( ${ }^{\text {nd }}$ ed., pp. 1-39). Boston: Allyn \& Bacon.

Triandis, H.C. (1995). Individualism \& Collectivism. Boulder, CO: Westview Press.

Trommsdorff, G. (2001). Eltern-Kind-Beziehungen aus kulturvergleichender Sicht [Parent-Child Relations from a Cross-Cultural Perspective]. In: S. Walper/R. Pekrun (Eds.). Familie und Entwicklung: Aktuelle Perspektiven der Familienpsychologie (pp. 36-62). Göttingen, Germany: Hogrefe.

Trommsdorff, G. (in press a). Entwicklung im kulturellen Kontext [Development in a Cross-Cultural Context]. In: G. Trommsdorff/H.-J. 
Kornadt (Eds.), Enzyklopädie der Psychologie: Themenbereich C. Theorie und Forschung: Serie VII. Kulturvergleichende Psychologie: Band 2. Kulturelle Determinanten des Erlebens und Verhaltens. Göttingen, Germany: Hogrefe.

Trommsdorff, G. (in press b). Intergenerational Relations and Cultural Transmission. In: U. Schönpflug (Ed.). Perspectives on Cultural Transmission. Oxford, UK: Oxford University Press.

Trommsdorff, G. (in press c). Parent-Child Relations Over the LifeSpan. A Cross-Cultural Perspective. In: K.H. Rubin/O.B. Chung (Eds.). Parenting Beliefs, Behaviors, and Parent-Child Relations. A Cross-Cultural Perspective. New York: Psychology Press.

Trommsdorff, G./Dasen, P.R. (2001). Cross-Cultural Study of Education. In: N.J. Smelser/P.B. Baltes (Eds.). International Encyclopedia of the Social and Behavioral Sciences (pp. 3003-3007). Oxford, UK: Elsevier.

Trommsdorff, G./Friedlmeier, W. (2004). Zum Verhältnis zwischen Kultur und Individuum aus der Perspektive der kulturvergleichenden Psychologie [The Relation Between Culture and Individual from the Perspective of Cross-Cultural Psychology]. In: A. Assmann, U. Gaier/G. Trommsdorff (Eds.). Positionen der Kulturanthropologie (pp. 358-386). Frankfurt a. M., Germany: Suhrkamp.

Trommsdorff, G./Komadt, H.-J. (2003). Parent-Child Relations in Cross-Cultural Perspective. In: L. Kuczynski (Ed.). Handbook of Dynamics in Parent-Child Relations (pp. 271-306). Thousand Oaks, CA: Sage.

Trommsdorff, G./Mayer, B./Albert, I. (2004). Dimensions of Culture in Intra-Cultural Comparisons: Individualism/Collectivism and Family-Related Values in Three Generations. In: H. Vinken/J. Soeters/P. Ester (Eds.). Comparing Cultures: Dimensions of Culture in a Comparative Perspective (pp. 157-184). Leiden, The Netherlands: Brill Academic Publishers.

Trommsdorff, G./Nauck, B. (2005a). Parenting and Social Demographics. Manuscript submitted for Parenting: Science and Practice.

Trommsdorff, G./Nauck, B. (Eds.). (2005b). The Value of Children in Cross-Cultural Perspective. Case Studies from Eight Societies. Lengerich, Germany: Pabst Sciences.

Trommsdorff, G./Schwarz, B. (in press). The "Intergenerational Stake Hypothesis" in Indonesia and Germany: Adult Daughters' and their Mothers' Perception of their Relationship. Current Sociology.

Trommsdorff, G./Zheng, G./Tardif, T. (2002). Value of Children and Intergenerational Relations in Cultural Context. In: P. Boski/F.J.R. van de Vijver/A.M. Chodynicka (Eds.). New Directions in Cross- 
Cultural Psychology. Selected papers from the Fifteenth International Conference of the Intemational Association for CrossCultural Psychology (pp. 581-601). Warszawa, Poland: Polish Psychological Association.

United Nations. Department of Economic and Social Affairs. Population Division. (2005). World Population Prospect, the 2004 Revision: Highlights. (ESP/P/WP/193). New York: United Nations.

Valsiner, J. (Ed.). (1988). Parental Cognition and Adult-Child Interaction. Stamford, CT: Ablex Publishing.

Wang, Q./Hsueh, Y. (2000). Parent-Child Interdependence in Chinese families: Change and Continuity. In: C. Violato/E. OddonePaolucci/M. Genuis (Eds.). The Changing Family and Child Development (pp. 60-69). Aldershot, UK: Ashgate.

Whiting, B.B./Whiting, J.W.M. (1975). Children of Six Cultures: A Psycho-Cultural Analysis. Cambridge, MA: Harvard University Press.

Ying, Y.W./Coombs, M./Lee, P.A. (1999). Family Intergenerational Relationship of Asian American Adolescents. In: Cultural Diversity and Ethnic Minority Psychology, 5, 350-363.

Zarit, S.H./Eggebeen, D.J. (2002). Parent-Child Relationships in Adulthood and Later Years. In: M.H. Bornstein (Ed.). Handbook of Parenting, Vol. 5. Practical Issues in Parenting (2 ${ }^{\text {nd }}$ ed., pp. 135-161). Mahwah, NJ: Erlbaum. 